\title{
Confinement dependent chemotaxis in two-photon polymerized linear migration constructs with highly definable concentration gradients
}

Hjortø, Gertrud Malene; Olsen, Mark Holm; Svane, Inge Marie; Larsen, Niels Bent

Published in:

Biomedical Microdevices

Link to article, DOI:

10.1007/s10544-015-9937-x

Publication date:

2015

Document Version

Peer reviewed version

Link back to DTU Orbit

Citation $(A P A)$ :

Hjortø, G. M., Olsen, M. H., Svane, I. M., \& Larsen, N. B. (2015). Confinement dependent chemotaxis in twophoton polymerized linear migration constructs with highly definable concentration gradients. Biomedical Microdevices, 17(2), 1-10. https://doi.org/10.1007/s10544-015-9937-x

\section{General rights}

Copyright and moral rights for the publications made accessible in the public portal are retained by the authors and/or other copyright owners and it is a condition of accessing publications that users recognise and abide by the legal requirements associated with these rights.

- Users may download and print one copy of any publication from the public portal for the purpose of private study or research.

- You may not further distribute the material or use it for any profit-making activity or commercial gain

- You may freely distribute the URL identifying the publication in the public portal 


\title{
Confinement dependent chemotaxis in two-photon polymerized linear migration constructs with highly definable concentration gradients
}

\author{
Gertrud Malene Hjort $\varnothing^{\dagger, \S, l, ~ M a r k ~ H o l m ~ O l s e n ~}{ }^{\dagger, l}$, Inge Marie Svane ${ }^{\ddagger}$, Niels B. Larsen *,† \\ ${ }^{\dagger}$ Department of Micro- and Nanotechnology, Technical University of Denmark, Ørsteds Plads 345E, \\ 2800 Kgs. Lyngby, Denmark
}

$\$$ Department of Haematology and Oncology, Center for Cancer Immune Therapy (CCIT), Copenhagen University Hospital at Herlev, 2730 Herlev, Denmark

${ }^{\S}$ Current address: Department of Neuroscience and Pharmacology, University of Copenhagen, 2200 Copenhagen, Denmark

" These authors contributed equally to this work.

* e-mail: niels.b.larsen@nanotech.dtu.dk

\begin{abstract}
Dendritic cell chemotaxis is known to follow chemoattractant concentration gradients through tissue of heterogeneous pore sizes, but the dependence of migration velocity on pore size and gradient steepness is not fully understood. We enabled chemotaxis studies for at least 42 hours at confinements relevant to tissue models by two-photon polymerization of linear channel constructs with crosssections from $10 \times 10 \mu \mathrm{m}^{2}$ to $20 \times 20 \mu \mathrm{m}^{2}$ inside commercially available chemotaxis analysis chips. Faster directed migration was observed with decreasing channel dimensions despite substantial cell deformation in the narrower channels. Finite element modeling of a cell either partly or fully obstructing chemokine diffusion in the narrow channels revealed strong local accentuation of the chemokine concentration gradients. The modeled concentration differences across a cell correlated well with the observed velocity dependence on channel cross-section. However, added effects due to
\end{abstract}


spatial confinement could not be excluded. The design freedom offered by two-photon polymerization was exploited to minimize the accentuated concentration gradients in cell-blocked channels by introducing "venting slits" to the surrounding medium at a length scale too small $(\leq 500 \mathrm{~nm})$ for the cells to explore, thereby decoupling effects of concentration gradients and spatial confinement. Studies in slitted $10 \times 10 \mu \mathrm{m}^{2}$ channels showed significantly reduced migration speeds indistinguishable from speeds observed in unslitted $20 \times 20 \mu \mathrm{m}^{2}$ channel. This result agrees with model predictions of very small concentration gradient variations in slitted channels, thus indicating a strong influence of the concentration gradient steepness, not the channel size, on the directed migration velocity.

Keywords: Two-photon polymerization, microchannels, chemotaxis, dendritic cells, chemokine, finite element modeling

\section{Introduction}

Directed cell migration (chemotaxis) towards a chemoattractant concentration gradient is essential for many body processes during development (Aman and Piotrowski 2010), in immune responses and healing processes (Germain et al. 2012), and in the metastasis of cancer cells (Sarvaiya et al. 2013). Chemotaxis involves cellular processes for navigating in and migrating through complex threedimensional (3D) microstructured environments. An important example is dendritic cells (DCs) responsible for surveying peripheral tissues for foreign objects followed by chemotaxis to the lymphatic vessels and the lymph nodes to present the objects encountered. Dendritic cells initially navigate through interstitial 3D structured connective tissue towards a gradient of the chemokine CCL21 secreted by lymphatic vessel endothelial cells, apparently in a fast integrin-independent process distinguished from the migration process on planar 2D surfaces (Laemmermann et al. 2008). The distance migrated in vivo is typically up to few hundreds of micrometers (Weber et al. 2013). Connective tissue is a heterogeneous microporous 3D environment with pore sizes from $1-20 \mu \mathrm{m}$ 
resulting from random mesh formation of fibrillar collagen (Wolf et al. 2013; Wolf et al. 2009).

Recent in vitro studies have reported a strong dependence of immune cell migration velocities on confinement in cellular sized channels, either in the absence (Faure-Andre et al. 2008) or presence of chemoattractant gradients along the channels (Ambravaneswaran et al. 2010; Irimia et al. 2007). Previous studies have relied heavily on molded silicone (PDMS) microchannel arrays that are not easily manufactured in larger numbers and with known risks of depleting solutes in low concentration due to adsorption or absorption into the bulk PDMS (Li et al. 2009). Furthermore, traversing cells may fully obstruct small diameter channels in bulk materials which results in strongly accentuated and poorly defined chemoattractant concentration gradients in the vicinity of the individual cell (Ambravaneswaran et al. 2010; Irimia et al. 2007).

We set out to produce a simple chip analysis system with a large degree of freedom in channel crosssection for analyzing dendritic cell chemotaxis in well-defined chemokine concentration gradients over several days. Two-photon polymerization of monomer or prepolymer resins offers full 3D design flexibility at the sub-micron to millimeter length scales (LaFratta et al. 2007). The upper limit of millimeters is effectively given by the low writing speeds achievable using the combination of currently available instrumentation, resins, and photoinitators. Thus, writing of entire analysis chips by two-photon polymerization for routine biological analysis is unlikely to be a feasible option in the foreseeable future. In a previous publication we demonstrated how to overcome this problem by writing the targeted 3D microstructured cell migration scaffolds inside the closed microfluidic systems of a commercially available chip designed for bulk migration analysis (Olsen et al. 2013). Here, we employed the methodology to produce parallel arrays of linear channels with well-defined square cross-sections from $10 \times 10 \mu \mathrm{m}^{2}$ to $20 \times 20 \mu \mathrm{m}^{2}$ and analyzed the average transmigration velocity of dendritic cells in the presence of a stable chemokine concentration gradient. Fabrication of the construct within a larger microfluidic system allowed for direct comparison of migration of dendritic cells within a confined microenvironment to their migration in the unstructured surroundings. Furthermore, we explored a solution to the intrinsic shortcomings of directed migration studies in closed channels of cell sized cross-sectional areas caused by spatial obstruction of solute (chemokine) 
diffusion by the cell. The sub-micrometer writing resolution of two-photon polymerization allowed for the introduction of solute "venting slits" along the ceiling of closed microchannels. The slits of width $\leq 500 \mathrm{~nm}$ were spatially inaccessible to the migrating cells but permitted continuous equilibration of the chemokine concentration within the channel to the outside bulk gradient concentration. Cells were observed to migrate at much reduced average speed in slitted channels of equal cross-sectional dimensions, indicating that chemokine gradient steepness is dominant in controlling the DC migration velocity in a confined microenvironment.

\section{Materials and methods}

\subsection{In-chip fabrication of cell migration channels}

Two-photon polymerization was performed on a Nanoscribe Photonic Professional system (Nanoscribe, Eggenstein-Leopoldshafen, Germany). The Nanoscribe system uses a $780 \mathrm{~nm}$ TiSapphire laser emitting $150 \mathrm{fs}$ pulses at $100 \mathrm{MHz}$ with a maximum power of $100 \mathrm{~mW}(20 \mathrm{~mW}$ at the sample surface) and is equipped with a 100x, 1.4 NA oil immersion objective. The substrate is placed in a holder that fits into a piezo $\mathrm{x} / \mathrm{y} / \mathrm{z}$ stage. Writing is done by controlling the laser in time and moving the stage in $\mathrm{x}, \mathrm{y}$ and $\mathrm{z}$. Structures were produced in a liquid acrylate based resin (IP-L 780, Nanoscribe). Writing speeds ranged from $600 \mu \mathrm{m} / \mathrm{s}$ to $1200 \mu \mathrm{m} / \mathrm{s}$ depending on the depth of writing into the resin: Larger writing depths caused loss of light intensity, and the writing speed was reduced accordingly to retain complete cross linking and structural rigidity. The structure consists of two parts: a horizontal array of closed microchannels situated on the chip channel bottom and a vertical blocking wall stretching from the top of the microchannel array to the ceiling of the chip channel (Fig. 1). The blocking wall was written in order from the largest to smallest writing depths to minimize intense scattering of the laser beam from already polymerized structures. Thus, the first layers written are furthest away from the objective and the surface of the substrate. The remainder of the structure was written in the opposite order from the smallest writing depths to the largest to ensure physical attachment to the chip bottom. Writing free-floating lines in the liquid resin was not possible due to 
thermal convection causing the individual written lines to float away prior to the next line being polymerized.

We have previously reported on the detailed fabrication process (Olsen et al. 2013). In brief, the polymer chip ( $\mu$-Slide Chemotaxis3D, ibidi, Martinsried, Germany, see Fig. 1a) was mounted on the piezo stage via fixation with Fixogum to a custom made aluminum adaptor. A drop of resin was placed on one channel inlet for the channel to fill by capillary forces. Residual resin on the inlet was removed with tissue. An initial measurement of the channel dimensions was performed by the autofocus system to determine the required structure height to fill the channel. Development was done by filling the reservoirs with 2-propanol and emptying after $10 \mathrm{~min}$. The process was repeated three times.

The chip reservoirs and the migration construct were surface coated with poly(ethylene glycol) diacrylate (PEGDA) to increase surface hydrophilicity and ensure complete filling of the channel structures with collagen and avoid bubble formation. Briefly, the chip channel structures were wetted by filling each reservoir with $65 \mu 170 / 30 \mathrm{EtOH} /$ water and then emptying the reservoirs by pipetting. Subsequently $65 \mu \mathrm{L}$ of $10 \mathrm{mM}$ PEGDA (1000 g/mol) and $2 \mathrm{mM}$ 4-benzoyl benzylamine hydrochloride (Bz) in phosphate buffered saline (PBS) (all from Sigma Aldrich) were added to each of the two reservoirs in the chip. To aid wetting the photoreactive solution must be added before the ethanol has completely evaporated from the channel structure. All inlets were plugged and the chip was exposed to UV light for $15 \mathrm{~min}\left(32.4 \mathrm{~J} / \mathrm{cm}^{2}\right)$ using a custom built photoreactor with a broad illumination maximum from 330-380 nm (Philips Cleo S-R fluorescent tubes). After exposure the chip reservoirs were rinsed 3 times with water. Ultimately the chip was sterilized by flushing the reservoirs with ethanol in a laminar flow bench and left to dry for $24 \mathrm{~h}$.

Confocal micrograph stacks were acquired with Zeiss LSM 5 and LSM 700 microscopes (Carl Zeiss, Oberkochen, Germany) with a 40x, 1.2 NA (numerical aperture) water immersion objective, using excitation light at $488 \mathrm{~nm}$ and collecting emitted light from $515-550 \mathrm{~nm}$. The recorded stacks were processed into 3D reconstructions using ImageJ (Rasband 1997-2012). 


\subsection{Generation of monocyte-derived dendritic cells}

CellGro DC serum-free medium, GM-CSF, IL-4, IL-1 $\beta$, TNF- $\alpha$ and IL-6 were all obtained from CellGenix (Freiburg, Germany). PGE $_{2}$ was obtained from Sigma-Aldrich. Iscoves modified Dulbecco's medium (IMDM) and human AB-Serum were acquired from Lonza (Basal, Switzerland), penicillin / streptomycin (P/S) and Fetal Bovine Serum (FBS) from Invitrogen (Life Technologies, Paisley, UK). $\mathrm{NaHCO}_{3}$ solution (7.5\%), 10x MEM solution, and collagenase (Clostridium Histolyticum, cell culture tested) were from Sigma-Aldrich, PureCol (collagen I) solution from Advanced Biomatrix (San Diego, CA), and recombinant human CCL21 from R\&D Systems (Minneapolis, MN).

Leukapheresis was done on healthy blood donors after informed consent followed by separation using elutriation (Terumo BCT, Lakewood, CO) and subsequent freezing of monocytes (80-90\% pure as determined by flow cytometry on CD14). Thawed monocytes with a viability $>99 \%$ were cultured for five days in culture plates $(\varnothing 21 \mathrm{~cm})$ at $5 \cdot 10^{5}$ cells $/ \mathrm{mL}$ in CellGro DC medium supplemented with $1000 \mathrm{U} / \mathrm{mL}$ GM-CSF and $250 \mathrm{U} / \mathrm{mL}$ IL-4 to produce immature DCs. Maturation of DCs was induced for 2 days by adding $1000 \mathrm{U} / \mathrm{ml}$ TNF- $\alpha, 1000 \mathrm{U} / \mathrm{mL}$ IL- $1 \beta, 1000 \mathrm{U} / \mathrm{mL}$ IL-6, and $1 \mu \mathrm{g} / \mathrm{mL} \mathrm{PGE}_{2}$ (Jonuleit et al. 1997). Harvest of DCs was performed by aspiration followed by cold incubation of the remaining cells in PBS with EDTA (5 mM) and subsequent scraping of cells followed by freezing of DCs in aliquots ( $90 \%$ human serum / 10\% DMSO).

\subsection{Collagen gel and DC loading in chips with constructs}

Mature DCs were thawed and transferred to pre-warmed IMDM with $10 \%$ FBS and $1 \% \mathrm{P} / \mathrm{S}$. The DCs were centrifuged at $220 \mathrm{~g}$ for $5 \mathrm{~min}$. Medium with DMSO was removed and the cells were left to acclimatize for $30 \mathrm{~min}$ at room temperature in fresh medium. The cells were centrifuged and resuspended at $4 \cdot 10^{6}$ cells $/ \mathrm{ml}$. A collagen mixture with cells was prepared according to the ibidi manual. Briefly, $10 \mu \mathrm{l}$ of $\mathrm{NaHCO}_{3}(7.5 \%)$ was mixed with $20 \mu \mathrm{L}$ of $10 \mathrm{x}$ MEM solution. After addition and mixing with $150 \mu \mathrm{L}$ of PureCol solution, $90 \mu \mathrm{L}$ of DC suspension was added and the mixture was applied to the chip for polymerization at $37^{\circ} \mathrm{C}$ for $30 \min$ (either $6 \mu \mathrm{L}$ inside the ibidi channel or 60 
$\mu \mathrm{L}$ in the sink reservoir). After collagen polymerization, the sink and source reservoirs were filled with medium alone and medium with added CCL21 $(60 \mathrm{nM})$, respectively. In the cases where the cells were loaded in the sink reservoir, only the source reservoir was filled upon collagen polymerization. The final collagen concentration was $1.67 \mathrm{mg} / \mathrm{mL}$.

\subsection{Quantitating the linearity and temporal stability of protein gradients}

Chips without constructs were loaded with collagen solution in the ibidi chip channel and incubated for $30 \mathrm{~min}$ to allow collagen polymerization, as described above. The source reservoir was filled with $60 \mu \mathrm{L} 0.1 \mathrm{mg} / \mathrm{mL}$ rhodamin-labelled streptavidin (Sigma-Aldrich) in PBS, and the sink resorvoir with $60 \mu \mathrm{L}$ PBS. The fluorescence in the chip channel was visualized by confocal microscopy at selected time points from $2 \mathrm{~h}$ to $42 \mathrm{~h}$, and the chip was placed in the incubator at $37^{\circ} \mathrm{C}$ between visualization events. Confocal microscopy was employed to limit the intense fluorescence signal from the $600 \mu \mathrm{m}$ high reservoirs next to the $70 \mu \mathrm{m}$ high ibidi channel of interest, although the former signals could be not be completely eliminated when using a lower magnification objective to visualize the entire chip channel in a single image.

\subsection{Time-lapse microscopy of DC migration}

We monitored DC migration using a custom made time lapse setup based on an inverted phase contrast microscope (Axiovert 100, Carl Zeiss) with a 20x phase contrast objective. The plugged chip with loaded DCs was mounted on a computer controlled translation stage, holding a temperature controlled $\left(37^{\circ} \mathrm{C}\right)$ humidified incubation chamber supplied with $5 \% \mathrm{CO}_{2}$ in air. DC migration was tracked for up to 40 hours. Slight positional variations in the stage position during time-lapse recordings were corrected by use of the TurboStack plugin for ImageJ (Thevenaz et al. 1998). The faint outlines of the DC dendrites within the microporous constructs were subsequently enhanced by subtracting the average (static) image of the construct from all images in the time-lapse sequence, and adding the subtracted images into the green channel of the recorded phase contrast images. Thus, the non-static cells will appear with a green tint in the final movies. The mean migration velocity was 
calculated as the microchannel length divided by the time difference in cell entry and exit of the microchannel.

\subsection{Collagenase treatment of construct}

After experimentation, the IPL channel structures were collagenase treated for removal of collagen and cells: collagenase solution $(0.5 \mathrm{mg} / \mathrm{ml}$ in PBS $)$ was added to the reservoirs and the channel inlets of the chip. The chip was incubated for 1 hour at $37^{\circ} \mathrm{C}$, the collagenase solution was withdrawn from the reservoirs, and the chip reservoirs were washed with water and then ethanol. Before reuse, the chip reservoirs were washed once more in sterile water, and the reservoirs and structures were completely emptied by applying suction to the channel after plugging the reservoir inlets.

\subsection{Finite element modeling}

The concentration gradient profile of chemoattractant in individual microchannels was modelled using the finite element modelling package COMSOL 4.3b (COMSOL AB, Stockholm, Sweden). A single microchannel was assumed to be representative of the entire channel array, since chemoattractant diffusion between neighboring channels can only occur at their endpoints. The relevant chemoatttractant, CCL21, is predicted to have a diffusion constant of $1.0 \cdot 10^{-10} \mathrm{~m}^{2} / \mathrm{s}$ in pure water, which may be reduced by a factor of 2-3 when diffusing in aqueous polymer networks (Ogston et al. 1973; Wang and Irvine 2013). Previous interaction studies did not show any binding of CCL21 to fibrillar collagen I (Haessler et al. 2011; Wang and Irvine 2013), which greatly simplifies the numerical modeling. Modeling was performed and is reported using diffusion constants corresponding to pure water $\left(1 \cdot 10^{-10} \mathrm{~m}^{2} / \mathrm{s}\right)$ and to strongly reduced diffusivity $\left(3 \cdot 10^{-11} \mathrm{~m}^{2} / \mathrm{s}\right)$. Channel boundary conditions were set as the CCL21 concentrations predicted at the endpoints of a construct located at the center of the chip channel and for a linear concentration gradient from the source $(60 \mathrm{nM})$ to the sink $(0 \mathrm{nM})$. Equilibrium was initially established by modeling the empty channel for 7200 seconds in agreement with the first sampling times in the time lapse experiments. A model of a traversing cell was then introduced as a channel segment of much reduced (100x lower) diffusion constant moving at constant rate from low towards higher concentration. A non-zero diffusion constant was chosen to 
avoid spatial discontinuities in the transport properties when translating the cell-mimicking segment through the channel. The length of the modeled channel segment was chosen as the average dendritic cell length observed in the actual constructs, being $40 \mu \mathrm{m}$ in a $10 \times 10 \mu \mathrm{m}^{2}$ channel and $20 \mu \mathrm{m}$ in a 20 x $20 \mu \mathrm{m}^{2}$ channel. The channel segment of reduced diffusion coefficient progressed through the channel at a rate equal to the average migration velocity of dendritic cells in actual constructs, i.e. 6.0 $\mu \mathrm{m} / \mathrm{min}$ for a $10 \times 10 \mu \mathrm{m}^{2}$ channel and $4.5 \mu \mathrm{m} / \mathrm{min}$ for a $20 \times 20 \mu \mathrm{m}^{2}$ channel. Dendritic cells were estimated to only obstruct $75 \%$ of the $20 \times 20 \mu \mathrm{m}^{2}$ channel cross-section in the timelapse experiments. Accordingly, modeling used a moving segment of reduced diffusivity that only occupied $75 \%$ of the channel cross-section. The resulting concentration profiles were sampled every $120 \mathrm{~s}$ for $3600 \mathrm{~s}$.

\subsection{Statistical analysis}

Quantitative data are reported as mean \pm standard error of the mean (SEM), unless otherwise stated. Statistical significance was evaluated using Welch's t-test for two samples having possibly unequal variances (Welch 1947).

\section{Results and discussion}

\subsection{Two-photon polymerization enables full design freedom of migration constructs}

Conventional lithographic processes can produce structures in closed transparent microsystems but do typically not allow for spatial control of the structures in the vertical dimension. Molding against basrelief master structures is a common approach for shaping surface topography in 3D but molding cannot be applied directly in closed systems. Two-photon polymerization offers both arbitrary 3D topological shaping and direct structure fabrication within transparent microsystems. We employed two-photon polymerization of a photocurable liquid acrylate resin to manufacture linear microchannel migration constructs inside the closed microfluidic system of an injection molded commercially available polymer chip designed for chemotaxis analysis (Fig. 1a, $\mu$-Slide Chemotaxis3D, ibidi). Fig. $1 \mathrm{~b}$ shows computer rendered illustrations of the migration construct design that provides a parallel array of individual channels, each having square cross-sections of $10 \mathrm{x} 10 \mu \mathrm{m}^{2}, 15 \mathrm{x} 15 \mu \mathrm{m}^{2}$, or $20 \mathrm{x}$ 
$20 \mu \mathrm{m}^{2}$, respectively. Individual channels are separated by $4 \mu \mathrm{m}$ wide resin walls. The channel array is sealed off from the surrounding microfluidic system by a $4 \mu \mathrm{m}$ thick resin ceiling while the bottom surface of the microfluidic system functions as channel array floor. The full height of the microfluidic system is $70 \mu \mathrm{m}$, which is much higher than the sealed photopolymerized migration channels. A solid wall structure matching the full height of the microfluidic system is added to the microchannel array above the entrance to the channels to minimize unwanted cell migration on top of the construct ceiling instead of inside the construct channels. Fig. 1c shows the autofluorescence from a construct with an array of $10 \times 10 \mu \mathrm{m}^{2}$ channels written inside the microfluidic system of the chip. The bottom and top surfaces of the microfluidic system are not visible in the micrograph due to much lower autofluorescence from the chip polymer material.

The construct ceiling is designed to be either solid, thereby preventing both cell migration and chemokine transport, or to be porous with a characteristic dimension too small for the migrating cell to explore while large enough to enable unhindered chemokine transport. Porosity is introduced as an integral part of the construct design in the format of $500 \mathrm{~nm}$ wide slit openings in the ceiling running perpendicular to the migration channels every $5 \mu \mathrm{m}$, as illustrated in Fig. $1 \mathrm{~b}$ ("With slits"). Twophoton polymerization provides the required writing resolution below $500 \mathrm{~nm}$. The insert of Fig. 1c displays a bottom view of the autofluorescence from channels with "slitted" ceilings and documents faithful transfer of the designed slits into the written constructs. 
a

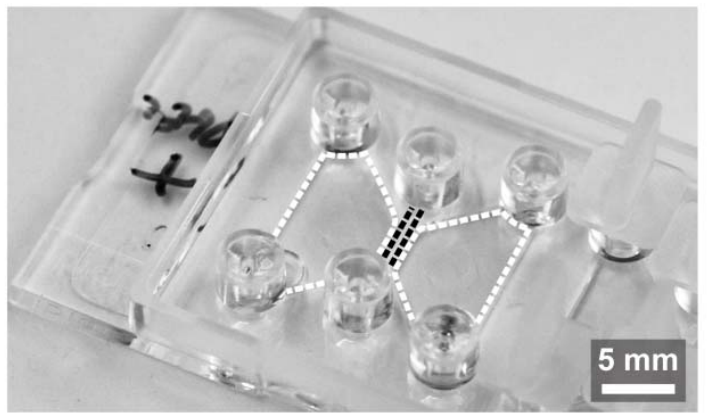

b

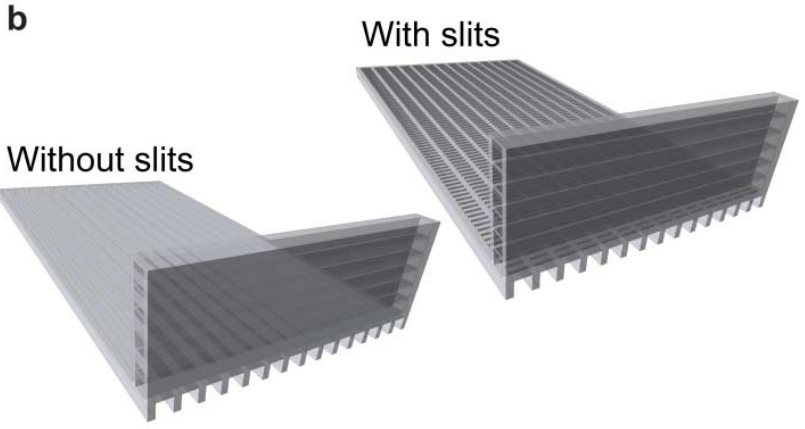

C

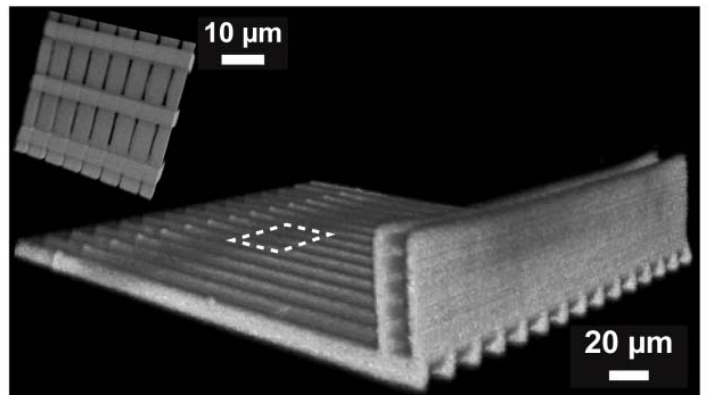

Fig. 1 High resolution cell migration constructs can be defined inside a chip system by two-photon polymerization. (a) Photograph of the fluidic chip used as platform for producing constructs of polymerized resin within a closed center channel (outlined with black dashes; 1 x w x h=1 mm x $2 \mathrm{~mm} \times 70 \mu \mathrm{m}$ ). Two connected reservoirs (outlined with white dashes; $\mathrm{h}=600 \mu \mathrm{m}$ ) on either side of the center channel function as source and sink, respectively, for generating a concentration gradient across the channel. (b) 3D drawings of the microchannel constructs, either without or with narrow venting slits in the ceiling of the channels. The tall barrier at the front of each construct is the same height as the chip channel, thus limiting the number of cells that can pass on top of the construct. (c) Confocal fluorescence micrograph of a construct fabricated inside a chip channel. The construct has square channel cross-sections of $10 \times 10 \mu \mathrm{m}^{2}$ and outer dimensions of $1 \times \mathrm{w} \times \mathrm{h}=400$ $\mu \mathrm{m} \times 200 \mu \mathrm{m} \times 70 \mu \mathrm{m}$. The polymer chip material at the top and bottom of the construct boundaries emits very faint autofluorescence and are not observed in this micrograph. Only the first $240 \mu \mathrm{m}$ of the construct length are visualized. The insert shows a magnified bottom view of the construct area outlined by white dashes to better visualize the $500 \mathrm{~nm}$ wide slits in the ceiling running perpendicular to the $10 \mu \mathrm{m}$ wide microchannel structures. 


\subsection{Stable biomolecular concentration gradients can be established for several days}

Dendritic cell migration through the linear constructs was visualized for up to $40 \mathrm{~h}$ in a matrix of fibrillar collagen I both inside and outside the channel arrays, thus calling for stable and linear chemokine concentration gradients on this time scale. The gradient stability and linearity was evaluated by filling a microfluidic chip with fibrillar collagen I and using fluorescently labelled streptavidin as a model protein for the chemokine (CCL21) to visualize the concentration variation by fluorescence microscopy. Fig. 2a shows a confocal fluorescence micrograph of the $1 \mathrm{~mm}$ wide chip channel system $2 \mathrm{~h}$ after loading of streptavidin in the chip source chamber. The fluorescence intensity decreases monotonically from the source side to the sink side (left to right in the micrograph), while being largely at constant levels at the same relative positions between the reservoirs (top to bottom in the micrograph). Fig. $2 \mathrm{~b}$ displays the fluorescence intensity averaged along the channel direction (top to bottom) for incubation times of $26 \mathrm{~h}$ and $42 \mathrm{~h}$, i.e. continuing beyond the maximum cell migration study times of $40 \mathrm{~h}$. The protein concentration gradients are found to be almost linear with a constant slope and a slowly increasing offset. The diffusion constants of streptavidin (56 kDa) and CCL21 (12 $\mathrm{kDa}$ ) are expected to differ by less than a factor of 2 based on the Stokes-Einstein relation (Miller 1924). Thus, it is likely that CCL21 concentration gradients will show equal linearity over similar time scales. 

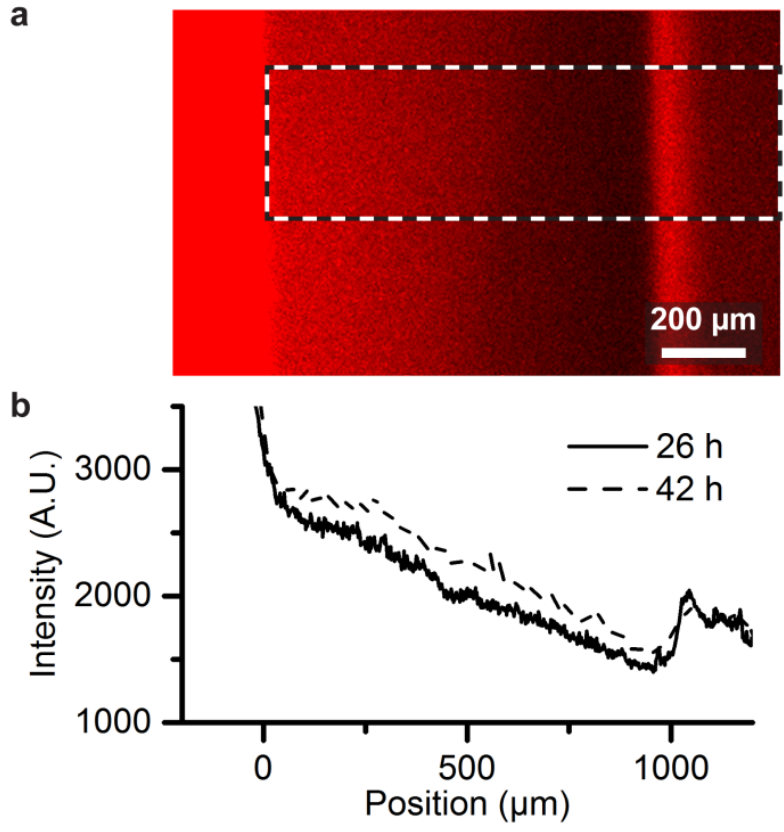

Fig. 2 Stable biomolecular concentration gradient in fibrillar collagen can be established in the chip channel for $>42$ h. (a) Confocal fluorescence micrograph in top view of rhodamine-labelled streptavidin in the microfluidic chip channel (center) $2 \mathrm{~h}$ after loading of the streptavidin in buffer in the source reservoir (far left) and loading of pure buffer in the sink reservoir (far right). (b) Averaged fluorescence intensity profiles across the chip channel after 26 and $42 \mathrm{~h}$ incubation, respectively, over an area of $1200 \mu \mathrm{m} \times 500 \mu \mathrm{m}$ as indicated by the dashed rectangle in (a). The higher intensities observed beyond the channel boundaries (positions less than $0 \mu \mathrm{m}$ and above $1000 \mu \mathrm{m})$ are due to the larger height in the reservoirs $(600 \mu \mathrm{m})$ compared to the channel $(70 \mu \mathrm{m})$.

\subsection{Channel confinement defines the cell morphology}

Dendritic cells loaded into the sink reservoir in a collagen hydrogel matrix migrated towards the opposing source chamber loaded with hydrogel containing CCL21. Time lapse microscopy was started 90 min after cell and CCL21 loading to allow initial establishment of a chemokine gradient within the $1 \mathrm{~mm}$ wide chip channel. Time lapse movies were recorded of cells traversing the four types of constructs of different microchannel cross-section and with a solid or porous microchannel ceiling. The resulting movies are included as Supporting Information M1-M4 in an image processed format to highlight the cells by a green tint. Fig. 3 shows shapshots from the image processed time lapse movies with arrows marking cells traversing the microchannel arrays. Many cells were found to move around the barrier at the channel array entrance and migrate above the microchannels. However, traversing cells are easily distinguished for quantitative analysis in the time lapse videos.

The cell morphology of the dendritic cells is substantially elongated at confinements smaller than $20 \mathrm{x}$ $20 \mu \mathrm{m}^{2}$. The average cell length in $10 \times 10 \mu \mathrm{m}^{2}$ (Fig. 3a) and $15 \times 15 \mu \mathrm{m}^{2}$ (Fig. 3c) channels is approximately $40 \mu \mathrm{m}$ and $25 \mu \mathrm{m}$, respectively. Assuming complete filling of the channel cross-section 
and a simplified rectangular cuboid cell morphology, the average cell volume is $4.0 \cdot 10^{3} \mu \mathrm{m}^{3}$ and $4.5 \cdot 10^{3} \mu \mathrm{m}^{3}$ in the two channel geometries. The rounded cell morphology in the $20 \mathrm{x} 20 \mu \mathrm{m}^{2}$ channels (Fig. 3d) is almost indistinguishable from cells outside the channels, indicative of a nearly spherical cell morphology. Assuming a constant cell volume of approx. $4.5 \cdot 10^{3} \mu \mathrm{m}^{3}$ in the different channel systems and approximating the cell morphology by a sphere the cell diameter is $20 \mu \mathrm{m}$, thus only filling $75 \%$ of the $20 \times 20 \mu \mathrm{m}^{2}$ square cross-section.
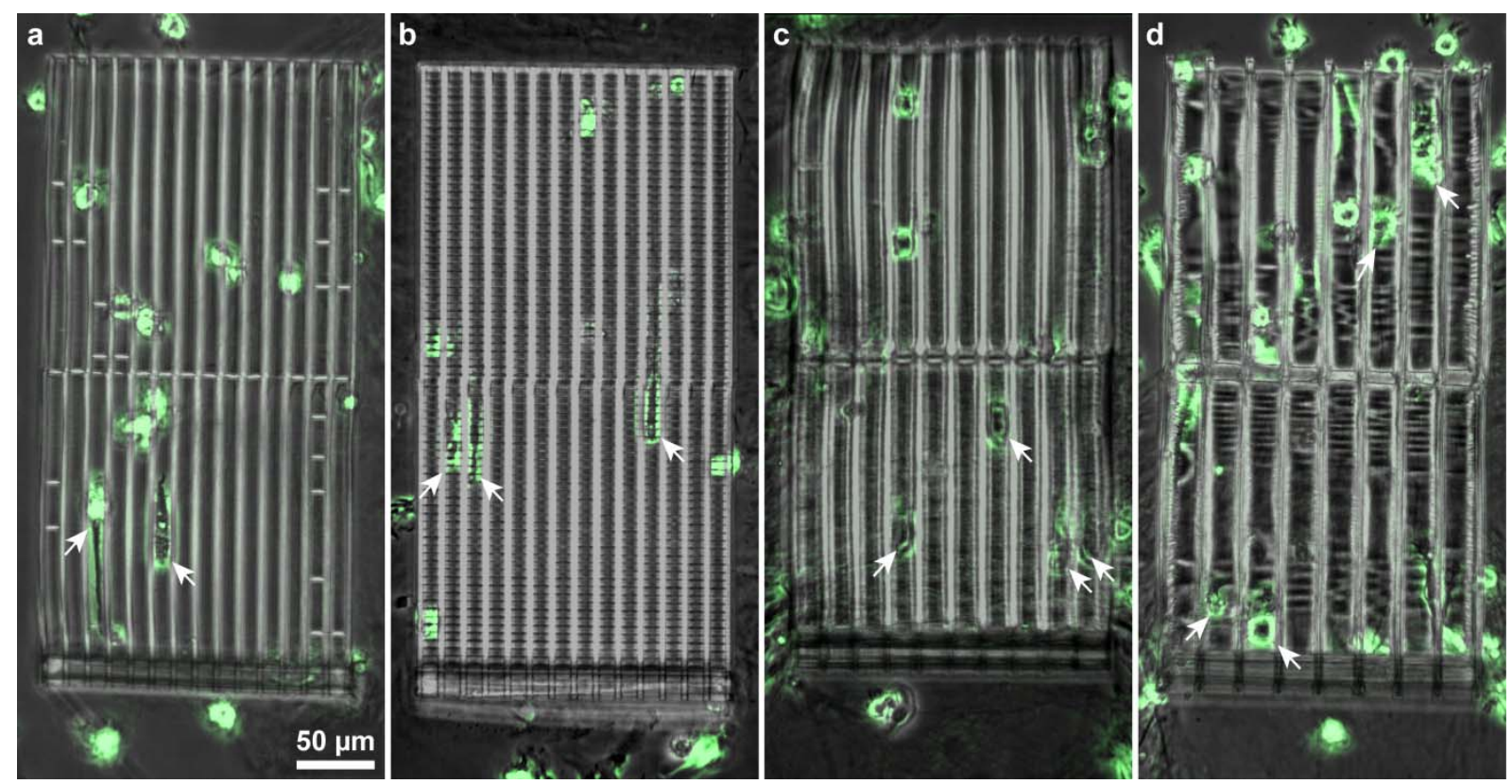

Fig. 3 Dendritic cells are markedly elongated in smaller channels. Top view phase contrast micrographs of DCs migrating through or around constructs with channel cross-sections of (a) $10 \times 10 \mu \mathrm{m}^{2}$, (b) $10 \times 10 \mu \mathrm{m}^{2}$ with slitted ceiling, (c) $15 \times 15 \mu \mathrm{m}^{2}$, or (d) $20 \times 20 \mu \mathrm{m}^{2}$. The CCL21 chemokine concentration increases from the bottom towards the top in all micrographs. Cells migrating inside the channels are marked by white arrows. The recorded phase contrast micrographs were processed to highlight non-static areas, i.e. mainly migrating cells, in green.

\subsection{Channel length affects the average transmigration velocity}

Dendritic cell chemotaxis through microchannels of different lengths, $200 \mu \mathrm{m}$ and $400 \mu \mathrm{m}$, but equal cross-section $\left(10 \times 10 \mu \mathrm{m}^{2}\right)$ resulted in a significantly higher mean transmigration velocity in the longer than the shorter channels (Fig. 4). 


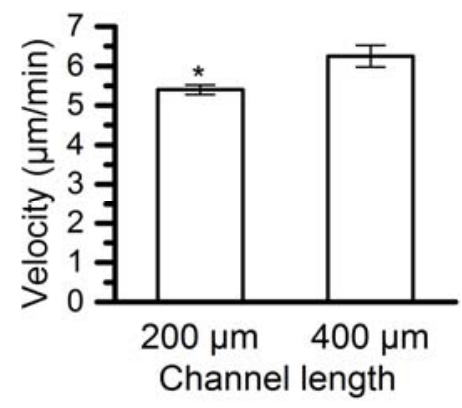

Fig. 4 Mean DC migration velocities towards the CCL21 source through $10 \times 10 \mu \mathrm{m}^{2}$ channels of different lengths differ significantly $(\mathrm{p}=0.04)$. Error bars show the standard error of the mean $(n \geq 4)$.

Given the equal degree of confinement, we considered if the observed difference could be caused by unintended varying accentuation of the diffusion gradient by fully confined cells acting as a diffusion barrier within each microchannel, as previously reported for neutrophils migrating in microchannels (Ambravaneswaran et al. 2010; Irimia et al. 2007). Finite element modelling (FEM) of the chemokine concentration profile as a diffusion-blocking cell traverses a $10 \times 10 \mu \mathrm{m}^{2}$ channel shows a strong increase in concentration difference between the cell ends, much beyond the level of the initially established concentration gradient (Fig. 5, solid blue lines). The effect was stronger in simulations using the higher CCL21 diffusion constant corresponding to a pure water environment (Fig. $5 \mathrm{~b}+\mathrm{d}$ ), as almost full equilibrium can be established with the chemokine concentrations at the microchannel inlet and outlet on time scales shorter than the cell migration. As discussed in the Materials and methods section, the actual CCL21 diffusion constant in the fibrillar collagen matrix is unknown but likely to be between the extremes used in the simulations. Thus, the level of concentration accentuation will be between the values extractable from Fig. 5(a+c) and Fig. 5(b+d). The accentuation across a $40 \mu \mathrm{m}$ long elongated cell is more pronounced in the longer channel (up to $20 \mathrm{nM}$ for $\mathrm{D}=10 \cdot 10^{-11} \mathrm{~m}^{2} / \mathrm{s}$ ) than in the shorter channel (up to $12 \mathrm{nM}$ for $\mathrm{D}=10 \cdot 10^{-11} \mathrm{~m}^{2} / \mathrm{s}$ ) due to the larger spatial separation of the inlet and outlet within the chip channel that holds a constant gradient of $60 \mathrm{nM} / \mathrm{mm}$ outside the construct. For both channel lengths, the concentration difference across a $40 \mu \mathrm{m}$ long cell is markedly higher than in an unobstructed channel $(2.4 \mathrm{nM})$. 

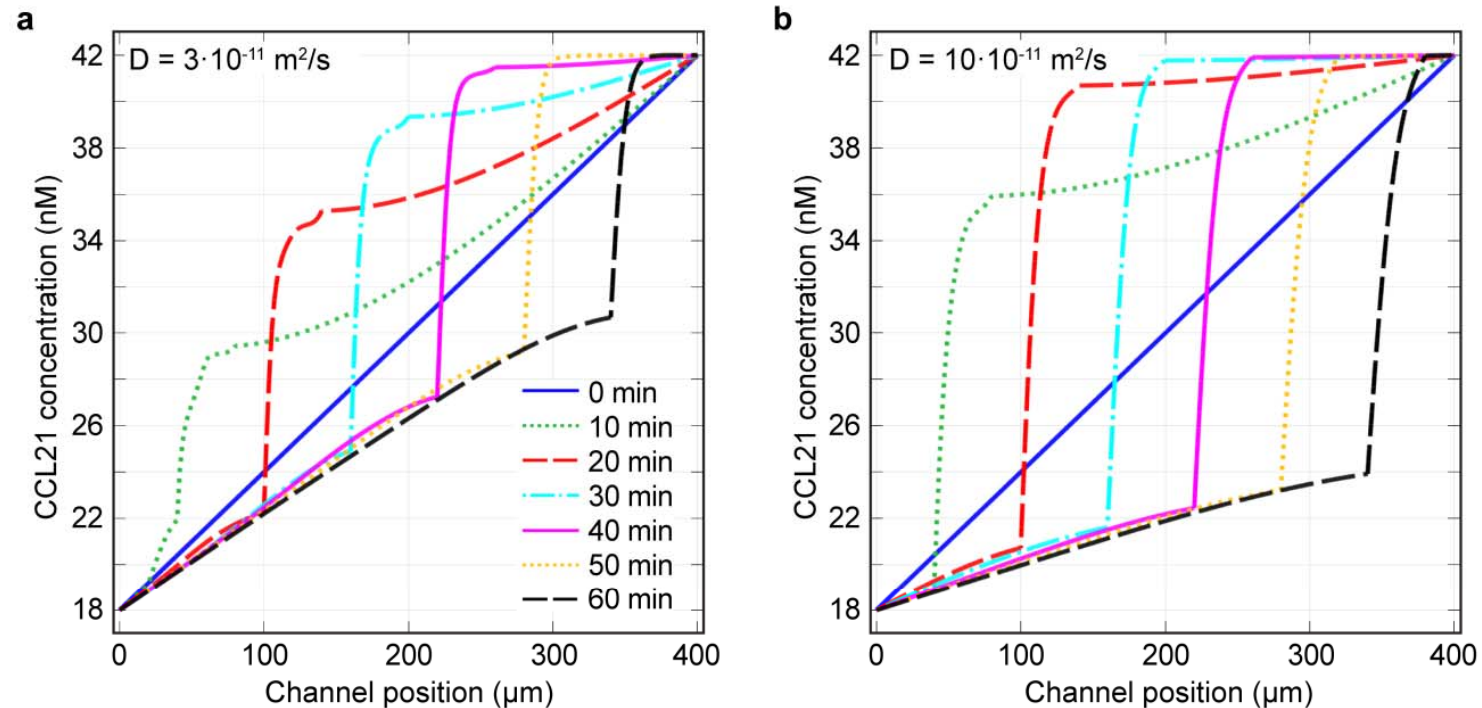

C

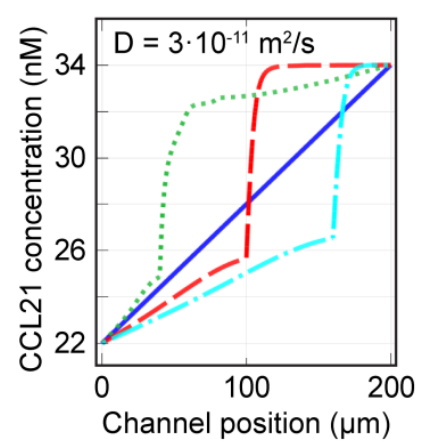

d

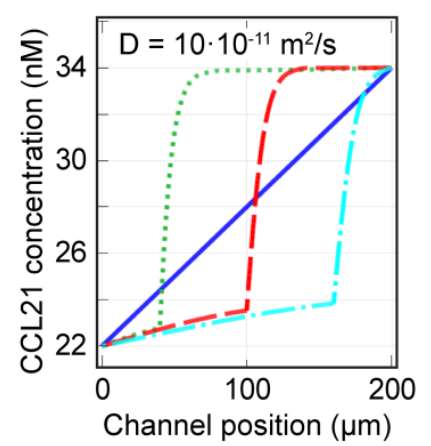

Fig. 5 Cell blockage of the microchannel results in strong accentuation of the chemokine gradient. Finite element modelling of the CCL2 1 chemokine concentration profile during passage of a $40 \mu \mathrm{m}$ long cell at a speed of 6 $\mu \mathrm{m} / \mathrm{min}$ through $10 \times 10 \mu \mathrm{m}^{2}$ channels with a length of $(\mathrm{a}+\mathrm{b}) 400 \mu \mathrm{m}$ or $(\mathrm{c}+\mathrm{d}) 200 \mu \mathrm{m}$. The CCL21 diffusion constant is approximately $10 \cdot 10^{-11} \mathrm{~m}^{2} / \mathrm{s}$ in aqueous media $(\mathrm{b}+\mathrm{d})$, and may be reduced to $3 \cdot 10^{-11} \mathrm{~m}^{2} / \mathrm{s}$ through fibrillar collagen $(a+c)$. The colored curves show the concentration profile at the indicated time points of the simulation.

\subsection{Transmigration velocities increase with increasing confinement in closed channels}

Fig. 6 presents the average migration velocity towards the CCL21 source through microchannel constructs of various cross-sections as well as through the surrounding fibrillar collagen matrix.

Migration through any construct results in a significantly higher directed migration velocity than the collagen matrix itself $(\mathrm{p}<0.006)$. Additionally, the average velocity is observed to increase with increasing cell confinement in constructs with solid ceilings, although the difference between $15 \times 15$ $\mu \mathrm{m}^{2}$ and $10 \times 10 \mu \mathrm{m}^{2}$ channels is not statistically significant. A similar trend was observed by Irimia et 
al. (Irimia et al. 2007) who investigated chemotactic transmigration of smaller neutrophils through microchannels down to $3 \times 10 \mu \mathrm{m}^{2}$ in cross-section. They mainly attributed the difference in velocity to blockage of chemokine diffusion by neutrophils in the smallest channels, and additionally suggested a change in cell propagation mode in the form of a continuous sliding motion along the walls. Later work by the same group on neutrophil chemotaxis in bifurcated microchannel systems supports the importance of channel blockage by the migrating cells in defining the active chemokine gradient (Ambravaneswaran et al. 2010). Other authors have investigated $\mathrm{T}$ cell migration through channels of varying cross-section in the absence of chemotactic gradients and observed a local maximum in speed for cross-sections around $7 \times 8 \mu \mathrm{m}^{2}$ (Jacobelli et al. 2010). Similarly, dendritic cell motility was investigated at tight confinement ( $4 \mu \mathrm{m}$ wide channels) in the absence of chemokines (Faure-Andre et al. 2008), showing comparable speeds to those reported in the smallest channels with chemokine gradients in Fig. 6. Thus, it may be difficult to conclude if the dominant effect on the directed migration velocity is the degree of spatial confinement or the effective chemokine concentration difference experienced by a cell within the microchannel.

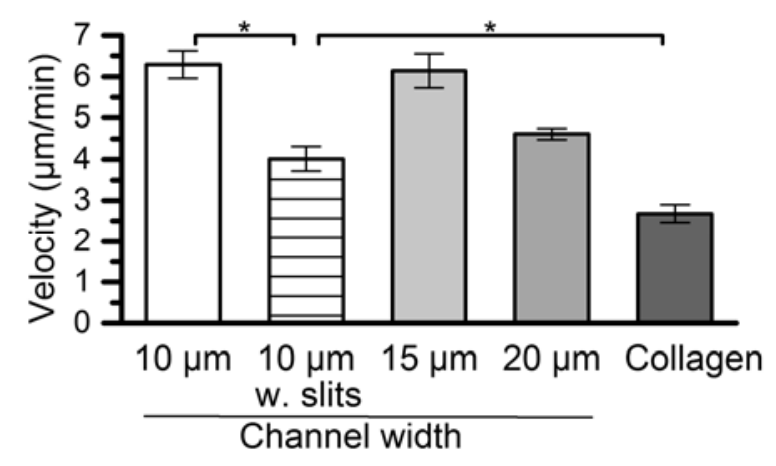

Fig. 6 Mean DC migration velocity towards the CCL21 source through $400 \mu \mathrm{m}$ long channels of different crosssection $\left(10 \times 10 \mu \mathrm{m}^{2}, 15 \times 15 \mu \mathrm{m}^{2}, 20 \times 20 \mu \mathrm{m}^{2}\right)$ filled with fibrillar collagen or through fibrillar collagen in the immediate vicinity of the channel structures. Constructs with $10 \times 10 \mu \mathrm{m}^{2}$ channels were tested without or with $500 \mathrm{~nm}$ wide slits in the channel ceilings. The asterisks show significant differences in velocity $(\mathrm{p}<0.01)$. Errors bars show the standard error of the mean $(n \geq 5)$. 


\subsection{Transmigration velocities do not increase with increasing confinement in slitted channels}

The extremely high 3D writing resolution achievable by two-photon polymerization combined with its ability to fabricate constructs within a closed volume offer a way to decouple the concentration accentuation from the spatial confinement effects. The comparatively large chip channel volume around the microchannels of the construct maintains a constant well-defined chemokine concentration gradient (Fig. 2). Gradient accentuation within the microchannel arises from lack of local diffusive transport through the microchannel walls to the surrounding volume. The introduction of designable through-holes of a smallest size much larger than the diameter of a CCL21 molecule enables efficient equilibration of the chemokine concentrations inside and outside the microchannels, even with a fully blocking cell in the channel. Obviously, the through-holes must be sufficiently small that the migrating cells are not affected during their exploration of the local environment.

Fig. 7 compares FEM results from a cell partially blocking a $20 \times 20 \mu \mathrm{m}^{2}$ channel with a solid ceiling (a+b) to a cell fully blocking a $10 \times 10 \mu \mathrm{m}^{2}$ channel with a ceiling perforated by nanoslits $(\mathrm{c}+\mathrm{d})$, as illustrated in Fig. 1b and visualized inside the chip in Fig. 1c. Both modelled systems show strongly reduced gradient accentuation compared to the results in Fig. $5(\mathrm{a}+\mathrm{b})$. Diffusion through the $20 \mathrm{x} 20$ $\mu \mathrm{m}^{2}$ channel is only partly blocked (approx. $75 \%$ ) due to the cell volume being too small to fill the channel, as previously discussed, which allows for gradient maintenance by axial diffusion. In contrast, the $10 \times 10 \mu \mathrm{m}^{2}$ channel largely maintains its chemokine gradient by radial diffusion though the nanoslits. The FEM results show almost equal CCL21 concentration differences across a cell in the two channel systems despite their widely different cross-section. This equivalence is reflected in statistically insignificant differences in their average migration velocity through the respective constructs (Fig. 6, "10 $\mu \mathrm{m}$ w. slits" vs. " $20 \mu \mathrm{m}$ "), while the difference between average migration speeds through the $10 \times 10 \mu \mathrm{m}^{2}$ constructs without or with slits is highly significant (Fig. 6, "10 $\mu \mathrm{m}$ " vs. "10 $\mu \mathrm{m}$ w. slits", $\mathrm{p}=0.0002)$. 

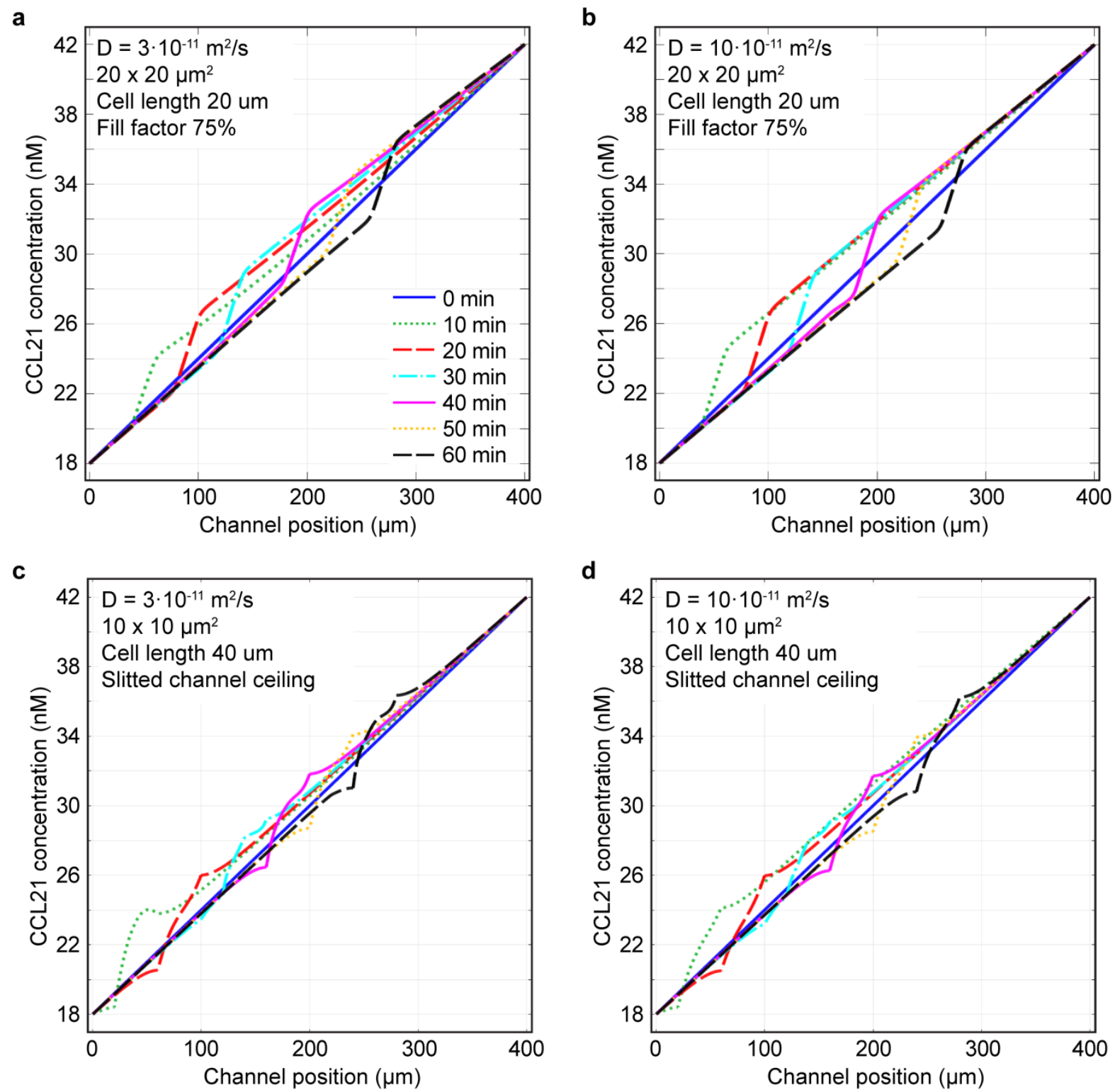

Fig. 7 Nanoslits in the channel ceiling strongly limit accentuation of the chemokine gradient in channels blocked by cells. $(\mathrm{a}+\mathrm{b})$ FEM of the CCL21 concentration profile during passage of a $20 \mu \mathrm{m}$ long cell at a speed of 4.5 $\mu \mathrm{m} / \mathrm{min}$ through $400 \mu \mathrm{m}$ long channels of cross-section $20 \times 20 \mu \mathrm{m}^{2}$ using a diffusion constant of (a) $3 \cdot 10^{-11} \mathrm{~m}^{2} / \mathrm{s}$ or (b) $10 \cdot 10^{-11} \mathrm{~m}^{2} / \mathrm{s}$. The cell is modeled as occupying $75 \%$ of the channel cross-section in its full length while $25 \%$ of the channel remains open. $(\mathrm{c}+\mathrm{d}) \mathrm{FEM}$ of the concentration profile during passage of a fully blocking 40 $\mu \mathrm{m}$ long cell at a speed of $4.5 \mu \mathrm{m} / \mathrm{min}$ in a $10 \times 10 \mu \mathrm{m}^{2}$ channel with a slitted channel ceiling (Fig. 1), using a diffusion constant of (c) $3 \cdot 10^{-11} \mathrm{~m}^{2} / \mathrm{s}$ or (d) $10 \cdot 10^{-11} \mathrm{~m}^{2} / \mathrm{s}$.

Fig. 6 shows that the chemokine concentration difference across the cell ends, $\Delta C_{\mathrm{CCL} 21}$, dominates over confinement effects in the constructs explored in this work. Additionally, simple finite element modeling of the chemokine gradient development during cell traversal seems adequate for predicting 
the local chemokine concentration variations. Fig. 8 correlates modeled $\Delta C_{\mathrm{CCL} 21}$ in configurations with or without spatial confinement to the measured mean directed migration velocity. The observed development in the velocity dependence on $\Delta C_{\mathrm{CCL} 21}$ is in good agreement with prior studies of dendritic cell migration through unstructured collagen gels with tunable chemokine gradients (Haessler et al. 2011). The simplest mechanism for describing the cellular regulation of chemotaxis is to assume proportionality in velocity with the difference in number of ligand-bound receptors (assuming Michaelis-Menten equilibrium) on opposing sides of the cell (Haessler et al. 2011; Wang and Irvine 2013). However, such a simple model may not accurately describe the complex signaling pathways involved in translating receptor/ligand interactions to directional cell velocity, and it is indeed not possible to obtain a good fit with the data of Fig. 8 using a linear model. A Hill-type equation (Hill 1910), $v=v_{\max } \frac{\Delta C_{C C L 21}^{\alpha}}{K^{\alpha}+\Delta C_{C C L 21}^{\alpha}}$ with the introduction of a non-linear scaling term $\alpha$, fits the data well but we have neither mechanistic support nor sufficiently accurate data to conclude on the appropriateness of the latter model.

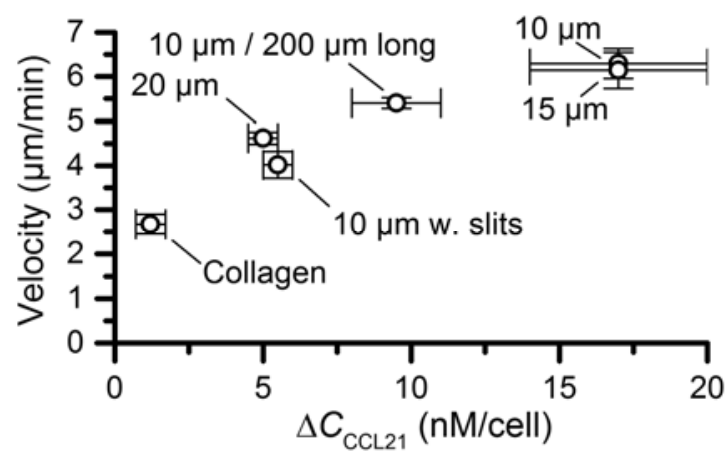

Fig. 8 Measured mean DC migration velocities monotonically depend on the modeled chemokine concentration across the cell ends within statistical error, independent of the degree of confinement. Vertical error bars show the standard error of the mean ( $\mathrm{n} \geq 4$; reproduced from Fig. 4 and Fig. 6). The concentration difference across a single cell, $\Delta C_{\mathrm{CCL} 21}$, is the mean of the values modeled using CCL21 diffusion constants of $3 \cdot 10^{-11} \mathrm{~m}^{2} / \mathrm{s}$ and $10 \cdot 10^{-11} \mathrm{~m}^{2} / \mathrm{s}$ (Fig. 5 and Fig. 7 ) with the horizontal error bars showing the span in modeled $\Delta C_{\text {CCL21 }}$ values. The uncertainty in $\Delta \mathrm{C}_{\mathrm{CCL} 21}$ for a cell in unstructured collagen is estimated to be $0.5 \mathrm{nM}$. The labels refer to the channel cross-section with all channel lengths being $400 \mu \mathrm{m}$ except for the " $10 \mu \mathrm{m} / 200 \mu \mathrm{m}$ long" data point. 


\section{Conclusions}

Two-photon polymerization provides a unique 3D design freedom at sub-cellular length scales that can be exploited to provide structurally well defined cell migration microenvironments while maintaining controllable chemokine concentration gradients, in contrast to existing closed microchannel systems traditionally used for analyzing chemotaxis in confined environments. Our results suggest a strong correlation of the directional migration velocity and the local chemokine concentration across the cell ends, while we observed very little if any effects of spatial confinements down to cellular length scales. Thus, human dendritic cells appear to migrate largely unhindered even when required to adopt to confinements leading to substantial cell elongation, although further confinement will eventually reduce or completely prevent their motion as we observed in previous work using confinements down to $5 \mu \mathrm{m}$ in cross-section (Olsen et al. 2013).

\section{Acknowledgements}

We thank Dr. Esben Kjær Unmack Larsen for assistance with photochemical modification of chip surfaces with PEGDA. We acknowledge financial support from the Danish Council for Independent Research, Technology and Production Sciences, grant\# 09-070021.

\section{References}

A. Aman, T. Piotrowski, Dev. Biol. 341, 20 (2010)

V. Ambravaneswaran, I.Y. Wong, A.J. Aranyosi, M. Toner, D. Irimia, Integr. Biol. (Camb) 2, 639 (2010)

G. Faure-Andre, P. Vargas, M. Yuseff, M. Heuze, J. Diaz, D. Lankar, V. Steri, J. Manry, S. Hugues, F. Vascotto, J. Boulanger, G. Raposo, M. Bono, M. Rosemblatt, M. Piel, A. Lennon-Dumenil, Science $322,1705(2008)$

R.N. Germain, E.A. Robey, M.D. Cahalan, Science 336, 1676 (2012)

U. Haessler, M. Pisano, M. Wu, M.A. Swartz, Proc. Natl. Acad. Sci. U. S. A. 108, 5614 (2011) 
A. Hill, J. Physiol. 40, iv (1910)

D. Irimia, G. Charras, N. Agrawal, T. Mitchison, M. Toner, Lab. Chip 7, 1783 (2007)

J. Jacobelli, R.S. Friedman, M.A. Conti, A. Lennon-Dumenil, M. Piel, C.M. Sorensen, R.S. Adelstein, M.F. Krummel, Nat. Immunol. 11, 953 (2010)

H. Jonuleit, U. Kühn, G. Müller, K. Steinbrink, L. Paragnik, E. Schmitt, J. Knop, A.H. Enk, Eur. J. Immunol. 27, 3135 (1997)

T. Laemmermann, B.L. Bader, S.J. Monkley, T. Worbs, R. Wedlich-Soeldner, K. Hirsch, M. Keller, R. Foerster, D.R. Critchley, R. Faessler, M. Sixt, Nature 453, 51 (2008)

C.N. LaFratta, J.T. Fourkas, T. Baldacchini, R.A. Farrer, Angew. Chem., Int. Ed. 46, 6238 (2007)

N. Li, M. Schwartz, C. Ionescu-Zanetti, J. Biomol. Screen. 14, 194 (2009)

C. Miller, Proc. R. Soc. Lond. A 106, 724 (1924)

A. Ogston, B. Preston, J. Wells, Proc. R. Soc. Lond. A 333, 297 (1973)

M.H. Olsen, G.M. Hjorto, M. Hansen, O. Met, I.M. Svane, N.B. Larsen, Lab Chip 13, 4800 (2013)

W.S. Rasband, ImageJ, U.S. National Institutes of Health, Bethesda, Maryland, USA. (, 1997-2012), http://imagej.nih.gov/ij/

P.J. Sarvaiya, D. Guo, I. Ulasov, P. Gabikian, M.S. Lesniak, Oncotarget 4, 2171 (2013)

P. Thevenaz, U.E. Ruttimann, M. Unser, IEEE Trans. Image Process. 7, 27 (1998)

Y. Wang, D.J. Irvine, Integr. Biol. (Camb) 5, 481 (2013)

M. Weber, R. Hauschild, J. Schwarz, C. Moussion, I. de Vries, D.F. Legler, S.A. Luther, T.

Bollenbach, M. Sixt, Science 339, 328 (2013)

B. Welch, Biometrika 34, 28 (1947)

K. Wolf, M. Te Lindert, M. Krause, S. Alexander, J. Te Riet, A.L. Willis, R.M. Hoffman, C.G. Figdor, S.J. Weiss, P. Friedl, J. Cell Biol. 201, 1069 (2013)

K. Wolf, S. Alexander, V. Schacht, L.M. Coussens, U.H. von Andrian, J. van Rheenen, E. Deryugina, P. Friedl, Semin. Cell Dev. Biol. 20, 931 (2009) 